Revista de Derecho

de la Pontificia Universidad Católica de Valparaíso

LV (Valparaíso, Chile, 2do semestre de 2020)

[pp. 195-224]

\title{
LA INDEMNIZACIÓN POR PRIVACIONES DE LIBERTAD ERRÓNEAS: UNA VISIÓN DESDE EL DERECHO COMPARADO
}

[Reparation for Erroneous Depravations of Liberty: a Perspective from

Comparative Law]

\author{
Mauricio DucE Julio* \\ Universidad Diego Portales, Chile
}

\begin{abstract}
RESUMEN
La evidencia disponible sugiere que nuestro mecanismo constitucional de indemnización por errores judiciales y la norma de responsabilidad por actuaciones del Ministerio Público son sumamente restrictivos, lo que dejaría desprotegidas a las víctimas de estos errores. Producto de esto se han presentado varios proyectos de reforma constitucional al artículo 19 no 7 letra i) que involucrarían también cambios al estatuto de responsabilidad del Ministerio Público. En este contexto, el presente trabajo intenta contribuir a alimentar un debate más informado sobre la futura regulación de esta materia revisando la existente en algunas experiencias del derecho comparado (casos de España, Alemania y Holanda) sobre compensación por privaciones de libertad erróneas. A partir de éstas se concluye que existen importantes espacios de mejora en Chile con el propósito de dar una cobertura más amplia a la protección de las víctimas de estos errores.
\end{abstract}

\begin{abstract}
Available evidence suggests that our constitutional compensation mechanism in cases of miscarriages of justice and the law that regulates responsibility from activities from prosecutors are excessively restricted to the point that might led their victims unprotected. As consequence of that many amendments to the article $19 \mathrm{n}^{\circ} 7$ (i) of the Constitution has been proposed that also involves changes in public prosecutor's statute. In this context, this article tries to contribute to a better-informed debate on future regulation on this topic by reviewing some experiences from the point of view of Comparative Law (Spain, Germany and Netherlands) regarding the compensation for erroneous depravations of liberty. By reviewing these experiences, I concluded that there are important possible improvements in Chile with the purposes of providing a better protection for the victims of such errors.
\end{abstract}

* Profesor Titular de la Facultad de Derecho de la Universidad Diego Portales. Magíster en Ciencias Jurídicas Universidad de Stanford. Dirección Postal: Avenida República 112, Santiago. Correo electrónico: mauricio.duce@udp.cl 
Palabras clave

Compensación - derecho comparado - indemnización por error judicial - justicia penal.

\section{Key Words}

Compensation - comparative law compensation for miscarriages of justice - criminal justice.

Recibido el 17 de julio de 2020 y aceptado el 16 de diciembre de 2020

\section{INTRODUCCIÓN"}

La Constitución de 1980 reguló el derecho a la indemnización por error judicial en su artículo 19 no 7 letra i). Con todo, un conjunto de prevenciones y temores manifestados en la elaboración del texto, impusieron exigencias altas para su procedencia ${ }^{1}$. De esta forma, la norma constitucional vigente permite indemnizar a quienes hayan sido condenados y a quienes han sido objeto de una persecución penal sin condena en ninguna instancia (cuando su caso haya concluido por un sobreseimiento). Sin embargo, para conseguir dicha indemnización la persona afectada por el error judicial debe obtener un pronunciamiento previo de la Corte Suprema en el que se declare que la resolución respectiva ha sido dictada en forma "injustificadamente errónea o arbitraria".

Más allá del debate doctrinal sobre esta norma², las estadísticas de la

** Trabajo realizado en el contexto de ejecución del proyecto Fondecyt regular $\mathrm{n}^{\circ} 1190016$ "Mecanismos de corrección y reparación de condenas e imputaciones erróneas: un análisis dogmático, empírico y comparado."

${ }^{1}$ Las preocupaciones estuvieron asociadas a los potenciales costos que una cláusula de este tipo podría generar para el erario público. Vid. Evans, Enrique, Los derechos constitucionales (Santiago, Editorial Jurídica de Chile, 1986), II, p. 114 o el efecto que podría producir en desincentivar una persecución penal vigorosa que, en ese momento, estaba en manos de los jueces del crimen. Vid. Barros, Enrique, Tratado de responsabilidad extracontractual (Santiago, Editorial Jurídica de Chile, 2006), p. 525.

${ }^{2}$ Una revisión de la literatura sobre la materia permite concluir que exista un consenso importante en identificar que se trata de una regla que impone exigencias bastante estrictas que limitan de una manera significativa la posibilidad de obtener una indemnización. La lista es extensa por lo que solo cito algunos de manera ejemplar: Barros, Enrique, cit. (n. 1), 1230 pp.; CARMOnA, Carlos, La responsabilidad del Estado-juez: Revisión y proyecciones, en Revista de Derecho Público, 66 (2004), pp. 307-357; Díaz, Nataly - Muñoz, Pamela, La responsabilidad del Estado-Juez: Buenas razones para proponer una acepción amplia de error judicial en Chile, en Revista de Derecho Público, 83 (2015), pp. 37-60; GARRIDO, Mario, La Indemnización por Error Judicial en Chile, en Revista Ius et Praxis, 5, (1999) 1, pp. 473-482; ZúNígA, Francisco. La Acción de indemnización por error judicial. Reforma constitucional. regulación infraconstitucional y jurisprudencia, en Estudios Constitucionales, 6 (2008) 2, pp. 15-41. 
Corte Suprema dan cuenta que su uso ha sido escaso y que las situaciones en que se ha concedido estas declaraciones previas son excepcionales. En efecto, entre el año 1980 y marzo de 2018 se presentaron 140 solicitudes, menos de cuatro al año, y en ocho ocasiones se dio lugar a ellas3. De estos, en uno sólo se dio lugar a la solicitud por haber estado la persona en prisión preventiva como consecuencia de una resolución judicial considerada como injustificadamente errónea ${ }^{4}$.

En forma más reciente, la implementación del nuevo sistema procesal acusatorio introdujo cambios importantes en cómo y quienes llevan adelante los casos penales. En particular, el Ministerio Público asumió la responsabilidad de ejercer la persecución penal, lo que obligó a regular mecanismos complementarios para obtener reparación por errores del sistema de justicia penal que no dependieran de los jueces. Así, la Ley Orgánica Constitucional del Ministerio Público ( ${ }^{\circ} 19.640$ de 15 de octubre de 1999) incorporó en su artículo $5^{\circ}$ una regla de responsabilidad civil

${ }^{3}$ Duce, Mauricio - Villarroel, Romina, Indemnización por error judicial: una aproximación empirica a la jurisprudencia de la Corte Suprema de los años 20062017, en Revista Politica Criminal, 14 (2019) 28, pp. 216-268, pp. 222-223. Una investigación reciente muestra como entre los años 2018 y 2019 se presentaron 14 solicitudes y ninguna de ellas fue aceptada. Vid. Huenuqueo, Camila, El ilusorio ejercicio del derecho a indemnización por error judicial consagrado en el artículo 19 $n^{\circ} 7$ letra $i$ de la Constitución como respuesta al uso de la prisión preventiva en Chile, (Santiago, Seminario para optar al grado de Licenciado en Ciencias Jurídicas Universidad Diego Portales, 2020), 51 pp., p. 20.

${ }^{4}$ Las limitaciones para usar esta cláusula con el propósito de indemnizar a personas objeto de prisión preventiva en el sistema acusatorio se explican por la doctrina restrictiva que durante buen tiempo tuvo la Corte Suprema en la materia. Así, desde el año 2.000 hasta mediados del año 2014 la Corte sostuvo como regla que esta cláusula no era aplicable al funcionamiento del nuevo sistema acusatorio ya que éste no contemplaba una institución equivalente al auto de procesamiento del sistema inquisitivo. La Corte tuvo un cambio radical en este tema el año 2014 al aceptar que esta expresión no podía restringirse sólo a una institución específica del sistema inquisitivo antiguo y cubría a imputados en el nuevo sistema que eran objeto de medidas cautelares personales (causa rol n 4921-2014 de 9 de junio de 2014). Bajo este nuevo criterio la Corte acogió el 2015 la solicitud declaración previa de error judicial que habilitó al recurrente a demandar la indemnización de perjuicios por haber estado en prisión preventiva y luego en arresto nocturno domiciliario en el desarrollo del proceso (causa rol $n^{\circ} 1579-15$ de 8 de julio de 2015). No puedo detenerme en este trabajo en un análisis detallado sobre la jurisprudencia y práctica generada en torno a la norma constitucional vigente ya que perdería el foco de este estudio centrado en el derecho comparado. Quien tenga interés en ello, puede revisar mi investigación previa recientemente publicada en la materia en la que abordo en extensión su análisis. Duce, Mauricio - Villarroel, Romina, cit. (n. 3), pp. 216268. 
por "Conductas injustificadamente erróneas o arbitrarias del Ministerio Público", ampliando de esta forma la posibilidad de obtener reparación por errores causados por el comportamiento de fiscales. Si bien la fórmula utilizada por nuestro legislador se inspira en el lenguaje de la Constitución para la indemnización por error judicial, se trata de un estatuto de responsabilidad separado ${ }^{5}$. Con todo, tampoco se ha traducido en la práctica en un derecho al que se pueda acceder fácilmente. Información proporcionada por el Consejo de Defensa del Estado indica que, entre el año 2005 y octubre de 2018, se habían presentado 147 demandas civiles en contra del Estado invocando esta regla, de las cuáles sólo seis habrían sido acogidas (dos de ellas con sentencias no ejecutoriadas a la fecha en que se proporcionó la información) ${ }^{6}$. Si bien se trata de cifras superiores a las de la norma constitucional, parecen estar todavía lejos de ofrecer una reparación intensa considerando los flujos de casos que maneja nuestro sistema de justicia penal ${ }^{7}$.

En consecuencia, si bien disponemos de normas constitucionales y legales que establecen un derecho a obtener una reparación por errores judiciales y actuaciones del Ministerio Público de distinta naturaleza, la práctica demuestra que se trata más bien de una posibilidad teórica. Es quizás esta misma percepción la que ha motivado la presentación de diez proyectos de reforma constitucional del actual artículo 19 no7 letra i) entre los años 2007 y 2017, varios de los cuáles también involucrarían reformas

${ }^{5}$ Véase, Dorn, Carlos, Responsabilidad extracontractual del Estado por actos del Ministerio Público, en Revista de Derecho Editada por el Consejo de Defensa del Estado, 13 (2005), pp. 13-26; CRISTI, María Francisca, Responsabilidad del Estado por conductas injustificadamente erróneas o arbitrarias del Ministerio Público, (Santiago, Tesina presentada a la Facultad de Derecho de la Universidad Finis Terrae para optar al grado de Magíster en Derecho Público, 2019), 40 pp.

${ }^{6}$ Oficio Ordinario $n^{\circ} 004084$ de 9 de noviembre de 2018. Información proporcionada por la periodista de El Mercurio, Andrea Chaparro, quien la utilizó en un artículo que publicó en el mismo diario el 27 de noviembre de 2018. Complementa estos datos una investigación realizada el año 2019 sobre sentencias de la Corte Suprema en materia de recursos de casación de fondo y de forma interpuestos en esta materia en el período comprendido entre mayo de 2007 y marzo de 2019. Allí se identificaron 22 sentencias, de las que en sólo cuatro casos se dio lugar a la acción de indemnización. CRISTI, María Francisca, cit. (n. 5), p. 32.

${ }^{7}$ Por ejemplo, en el período entre los años 2007 y 2016 hubo 48 recursos de revisión acogidos por la Corte Suprema en casos del sistema acusatorio, todos los que en principio debieran ser candidatos a obtener una indemnización por tratarse de condenas erróneas acreditadas ante la propia Corte. Véase, DuCE, Mauricio, Los recursos de revisión y la condena de inocentes en Chile: una aproximación empirica en el periodo 2007-2016, en Doctrina y jurisprudencia penal: Recursos de amparo y revisión, 30 (2017), pp. 3-40. 
al estatuto del Ministerio Público ${ }^{8}$. Todas estas propuestas se estructuran sobre la base de constatar la insuficiencia de los mecanismos actuales para dar adecuada satisfacción al derecho a la reparación. A la fecha, ninguna de ellas ha prosperado.

El debate sobre una nueva constitución que se ha abierto en el país ofrece una oportunidad para discutir sobre la regulación este derecho. Lo óptimo sería contar con una cláusula constitucional y otras de tipo legal que establezcan un equilibro más adecuado para ofrecer un derecho de reparación real y así compensar satisfactoriamente a quienes han sido víctimas de errores con graves consecuencias. Especialmente preocupa a este trabajo el caso de personas que han estado privadas de libertad durante el desarrollo del proceso sin que sus casos concluyan con una condena y en que esa privación de libertad pudo haberse evitado con un poco de mayor diligencia en la actuación de los actores del sistema. Llamaré a estas como privaciones de libertad erróneas. No pretendo instalar con ello una categoría dogmática, sino ocupar una etiqueta descriptiva del problema que lo permita diferenciar, por ejemplo, de privaciones de libertad ilegales. La preocupación en estos casos surge ya que la evidencia disponible muestra que el impacto negativo de estas privaciones de libertad es enorme en las personas que las sufren y en quienes los rodean'. Además, la evidencia disponible en Chile indica que se trata de un problema que ha crecido de

${ }^{8}$ De ellos ya hay cuatro proyectos que están archivados: Boletines no 5539-07 de 2007; n 5745-07 de 2008; n 7.277-07 de 2010; y, n 9.634-07 de 2014. Cinco aún se encuentran en tramitación, pero no han superado en primer trámite constitucional en la Cámara de Diputados: Boletines n 6083-07 de 2008; n 6310-07 de 2009; n ${ }^{\circ}$ 7699-07 de 2011; n 9513-07 de 2014; y, no 11.464-07 de 2017. Finalmente, existe un proyecto que fue aprobado por la Cámara de Diputados y enviado al Senado para discusión: Boletín n¹1342-07 de 2017, pero cuya tramitación no ha avanzado.

${ }^{9}$ No puedo detenerme en este punto, pero la evidencia comparada indica que ellas producen enormes daños psicológicos, económicos, familiares y sociales para quienes los sufren y su entorno familiar. Véase, Campbell, Katryn - Denov, Myriam, The burden of innocence: coping with a wrongful imprisonment, en Canadian Journal of Criminal Law and Criminal Justice, 46 (2004), pp. 139-163; Grounds, Adrian, Psychological Consequences of Wrongful Convictions and Imprisonment, en Canadian Journal of Criminal Law and Criminal Justice, 46 (2004), pp. 165-182; Sсотт, Leslie, It Never Ends: The Psychological Impact of Wrongful Convictions, en American University Criminal Law Brief, 5 (2010) 2, pp. 9-22; Clow, Kimberly - Leach, Amy-May - Ricciardelli, Rosemary, Life After Wrongful Convictions, en Cutler, Brian (editor), Conviction of the Innocent (Washington, APA, 2012), pp. 327-341. La escasa evidencia disponible en el ámbito nacional apunta en la misma dirección: Grau, Nicolás - Rivera, Jorge, Discriminación e impacto negativo de la prisión preventiva en la vida de las personas, en Revista, 93, 19 (2018), pp. 26-29. 
manera significativa en los últimos años y que, por lo mismo, afectaría a muchas personas anualmente ${ }^{10}$.

En este contexto, el propósito de este trabajo es contribuir al debate en nuestro país por medio de la presentación y del análisis de distintas formas en el que el derecho comparado se ha hecho cargo de regular la indemnización por privaciones de libertad erróneas. Debo señalar que la idea de indemnizar este tipo de errores normalmente no está recogida de manera tan explícita en las legislaciones comparadas. No obstante, indirectamente, la posibilidad de obtener reparación en estos casos se deriva de reglas generales de indemnización por el uso de la prisión preventiva. Así, desde el siglo XIX (al menos), diversos países de Europa han establecido reglas que permitían a personas que estuvieron presas durante el desarrollo del proceso penal (y que luego no fueron condenadas) obtuvieran algún tipo de indemnización por los daños que se les ocasionaron ${ }^{11}$. No se trata de normas pensadas exclusivamente desde la perspectiva del error en el uso de la privación de libertad, pero es evidente que esos casos también quedan cubiertos por estas reglas.

${ }^{10}$ Sólo el año 2018 las cifras de la Defensoría Penal Pública dan cuenta que hubo 3.153 imputados en prisión preventiva o internación provisoria cuyos casos no concluyeron con condenas (en un porcentaje importante objeto de absoluciones y sobreseimientos). De este total, 661 personas estuvieron más de seis meses privadas de libertad, con lo cual se está en presencia de privaciones no menores desde el punto de vista de su duración. Véase: Defensoría Penal Pública, Informe Estadístico 2018 (Santiago, 2018) [visible en internet: http://www.dpp.cl/repositorio/177/486]. No todas estas privaciones de libertad pueden haber sido erróneas. Asumiendo, a modo ejemplar, un escenario conservador en el que sólo en un $5 \%$ de ellos se produjo un error grave, eso nos daría 158 potenciales indemnizaciones en el año (33 personas cuya privación de libertad excedió los seis meses) (cabe señalar que este 5\% se toma a partir de estudios que han intentado cuantificar el porcentaje de condenas erróneas, por ejemplo en el trabajo de Gross y otros se cifra en un 4,1\% en delitos de pena de muerte en los Estados Unidos entre los años 1973 y 2004. Véase: Gross, Samuel - O'Brien, Barbara - Hu, Chen - Kennedy, Edward, Rate of False Convictions of Criminal Defendants Who are Sentenced to Death, en Proceedings of the National Academy of Sciences of the United States of America, 11 (2014) 20, pp. 7230-7235, p. 7233. Risinger, por su parte, el año 2007, establece una tasa de error entre 3,3\% y $5 \%$ en los delitos de violación-homicidio en el mismo país. Véase, Risinger, Michael, Innocent Convicted: An Empirically Justified Wrongful Conviction Rate, en The Journal of Criminal Law \& Criminology, 97 (2007) 3, pp. 761-806, p. 780).

${ }^{11}$ BORCHARD, Edwin, European Systems of State Indemnity for Errors in Criminal Justice, en Journal of the American Institute of Criminal Law and Criminology, 3 (1912), pp. 684-718, pp. 697-698. Domenech eso si llama la atención a que las soluciones europeas en esta materia están lejos de entregar una respuesta uniforme. Véase, Domenech, Gabriel, ¿Es mejor indemnizar a diez culpables que dejar a un inocente sin compensación?, en InDret, 4 (2015), pp. 1-42, p. 12. 
Debido a la enormidad de arreglos constitucionales y legales disponibles en la materia mi foco estará en algunos de estos mecanismos. Revisaré de manera principal la regulación española contenida en Ley Orgánica del Poder Judicial (Ley 6/1985 de 1 de julio de 1985) (en adelante la LOPJ) que establece el derecho a la indemnización por prisión preventiva en su artículo 294 y complementaré con una revisión de otros dos ejemplos de países europeos (Alemania y Holanda), pero que serán revisados con menor profundidad. El centro del análisis no estará en los extensos debates dogmáticos y jurisprudenciales de cada una de las instituciones, sino en la descripción de sus principales elementos y en entregar una visión de su práctica, de manera de tener una imagen concreta de la cobertura que efectivamente otorgan para contribuir a reparar a las víctimas de las privaciones de libertad erróneas.

\section{LA INDEMNIZACIÓN POR PRISIÓN PROVISIONAL ERRÓNEA EN ESPAÑA}

La Constitución española de 1978 contempla, al igual que la chilena, una norma que regula la indemnización por error judicial. Así, en el artículo 121 señala que: "Los daños causados por error judicial, asi como los que sean consecuencia del funcionamiento anormal de la Administración de Justicia, darán derecho a una indemnización a cargo del Estado, conforme a la ley" ${ }^{12}$.

De la simple lectura de esta norma, es posible apreciar como ella contempla dos vías reparatorias o títulos de imputación en contra del Estado. Por una parte, están los casos de "error judicial" y, por la otra, los daños causados como consecuencia del "funcionamiento anormal de la justicia". Ninguna de estas se haría cargo en forma directa de las privaciones de libertad erróneas. Con todo, una nota característica central de la regulación constitucional de este país es que le entrega al legislador un amplio margen de regulación de este derecho, en la medida que se atenga a los parámetros básicos contenidos en la Constitución ${ }^{13}$. En efecto, el artículo concluye con una remisión final que señala que el derecho se llevará a efecto "conforme a la ley". De esta forma, el legislador -al regular legalmente esta materia en los artículos 292 a 296 de la LOPJ de 1985-incluyó un tercer título de imputación en el artículo 294 que abarca a las personas que hayan sufrido prisión preventiva y luego hayan sido absueltas.

${ }^{12}$ Sobre la evolución legislativa y debate que llevo a la inclusión de este derecho en la constitución española de 1978 véase, ReBollo, Luis, Jueces y responsabilidad del Estado: el artículo 121 de la Constitución (Madrid, Centro de Estudios Constitucionales, 1983), pp. 77-118.

${ }^{13}$ Cobreros, Edorta, Funcionamiento anormal de la administración de justicia e indemnización, en Revista de Administración Pública, 177 (2008), pp. 31-69, p. 33. 
En lo que sigue analizaré los principales elementos de este tercer título de imputación, poniendo foco no tanto en el extenso debate doctrinario y jurisprudencial, sino más bien en la comprensión de su lógica y de cómo esta norma podría operar como un instrumento de compensación de privaciones de libertad erróneas.

\section{Algunas cuestiones generales sobre el contenido y funcionamiento}

En su texto vigente, el artículo 294.1 de la LOPJ establece que "Tendrán derecho a indemnización quienes, después de haber sufrido prisión preventiva, sean absueltos o haya sido dictado un auto de sobreseimiento libre, siempre que le hayan irrogado prejuicios."

El precepto contiene la regla básica que fija los contornos sobre los que rige la responsabilidad del Estado en esta materia, y que luego es complementado por los numerales 2 y 3 . Su redacción actual es fruto de una reciente decisión del Tribunal Constitucional de junio de $2019^{14}$ la que, según la doctrina, realizó un cambio radical en la forma en que se había planteado el debate respecto a quiénes efectivamente tendrían derecho a obtener una indemnización por este título de imputación e incluso respecto a los fundamentos del mismo ${ }^{15}$.

Dos observaciones iniciales antes de analizar algunos elementos con mayor detalle. En su forma actual, el artículo 294.1 parece establecer una regla muy abierta de indemnización ya que, en principio, entregaría este derecho a todos los que estuvieron en prisión preventiva y no fueron condenados. La regla no exigiría que la prisión preventiva haya sido decretada erróneamente como lo hace nuestra normativa constitucional ${ }^{16}$. Las únicas restricciones que parece imponer esta regla son las formas de término específicas que debe haber tenido el caso (absolución o auto de sobreseimiento libre ${ }^{17}$ ) y el que la privación de libertad haya arrojado 2019.

${ }^{14}$ STC 85/2019 de 19 de junio de 2019, en: BOE núm. 177, de 25 de julio de

${ }^{15}$ Medina, Luis, Razones para (no) indemnizar la prisión provisional seguida de absolución: guía explicativa del art. 294.1 LOPJ tras la STC 85/2019 de 19 de junio, en Revista Española de Derecho Administrativo, 200 (2019), pp. 1-41, p. 6.

${ }^{16} \mathrm{O}$ también la legislación constitucional de España tratándose de los errores judiciales. Véase, Cobreros, Edorta, El sistema de indemnización por prisión provisional indebida en la encrucijada, en Revista de Administración Pública, 209 (2019), pp. 13-44, p. 18.

${ }^{17} \mathrm{El}$ sobreseimiento libre equivale funcionalmente, aun cuando no con completa exactitud, al que se denomina como sobreseimiento definitivo en Chile y se encuentra regulado en los artículos 634, 637 a 640 y 643 de la Ley de Enjuiciamiento Criminal Española. 
perjuicios a quien requiere la indemnización. De cualquier manera, no pareciera tratarse de límites intensos.

Una segunda cuestión es que esta redacción se aparta de la lógica en que los tratados internacionales de derechos humanos regulan el derecho a indemnización en casos de privación de libertad. En efecto, ellos establecen un derecho de indemnización que se construye en la idea de la ilegalidad de la privación de libertad (ya sea entendida como contravención a las reglas del propio instrumento internacional como lo regula el artículo 5.5 del Convenio Europeo de Derechos Humanos o incluyendo también violaciones de legislación interna como el artículo 9.5 del Pacto Internacional de Derechos Civiles y Políticos) ${ }^{18}$. En consecuencia, la prisión preventiva decretada pudo haber sido perfectamente legal y acorde con disposiciones de derecho interno e internacional e igualmente daría lugar a la indemnización en el caso de que la persona que la ha sufrido sea absuelta o se la haya dictado un auto de sobreseimiento libre. Desde este punto de vista, se trata de un derecho que ofrece una cobertura muy superior al contenido en la legislación internacional de derechos humanos.

Esta apertura normativa tendría un cierto reflejo en las cifras del sistema. Entre los años 2000 a 2008 (al 30 de septiembre) se habrían presentado 1.453 solicitudes de indemnización por dicho concepto ${ }^{19}$ y entre 2015 y 2016 habrían sido otros $323^{20}$. En consecuencia, y tomando estos años como base, habría un promedio de alrededor de 160 solicitudes anuales, siendo el segundo título de imputación con más solicitudes en dicho país luego del funcionamiento anormal de la administración de justicia ${ }^{21}$.

En relación a sus resultados, sólo tengo disponibles los datos expuestos

${ }^{18}$ En general sobre la regulación internacional de esta materia: Mujızi, Jamil, The right to compensation for wrongful conviction/miscarriage of justice in international Law, en International Human Rights Law Review, 8 (2019), pp. 215-244. Sobre el Convenio Europeo: Trechsel, Stefan, Human Rights in Criminal Proceedings (United Kingdom, Oxford University Press, 2006), y Schabas, William, The European Convention on Human Rights (Oxford, Oxford University Press, 2015). Sobre el Pacto Internacional: Nowak, Manfred, U.N. Covenant on Civil and Political Rights: CCPR Commentary (Germany, N.P Engel Publisher, 2005).

${ }^{19}$ GonZÁlez, Augusto, Responsabilidad patrimonial del Estado en la administración de justicia (Valencia, Tirant lo Blanch, 2008), p. 276.

${ }^{20}$ RuIz DE VAlbuena, Irene, La justicia reduce su factura por errores judiciales (España, Cinco Días, El País Economía, 3 de noviembre de 2017) [https://cincodias. elpais.com/cincodias/2017/10/27/legal/1509097046_653926.html]

${ }^{21}$ Para el mismo período el flujo de casos de indemnización por error judicial fue de 99 el 2015 y 107 el 2016. En este último año, sólo en uno de ellos se admitió la responsabilidad del Estado. En materia de funcionamiento anormal, las reclamaciones administrativas de 2015 fueron 406 y el 2016 llegaron a 354. Véase, Ruiz de Valbuena, Irene, cit. (n.20). 
en el estudio que revisó su funcionamiento entre los años 2000 a 2008. En dicho período se habrían estimado favorablemente 50 solicitudes, es decir, sólo un 3,44\% del total ${ }^{22}$. Nuevamente se constata una diferencia importante entre un sistema normativo abierto y una situación en la práctica mucho más limitada.

Un estudio empírico más reciente arroja algunos datos relevantes a considerar para determinar los alcances prácticos de esta regla. En este se identifican 64 sentencias que concedieron indemnización a 70 personas en el período comprendido entre el año 2005 y el 2015 (hasta el 30 de junio) ${ }^{23}$. Asumiendo que en el período se mantuvo relativamente constante el número de solicitudes de indemnización (lo que parece bastante razonable a la luz del número del año 2015 que ya cité), no se habría producido un cambio muy radical en el otorgamiento de las indemnizaciones respecto de las cifras del período 2000 a 2008 expuestas.

Pero este estudio agrega algunos elementos adicionales relevantes de considerar. La media del monto indemnizado habría sido de EU\$ 42.295, pero con un nivel de variación bastante importante entre el caso con menor y el con mayor monto ${ }^{24}$. El tiempo promedio de privación de libertad de los indemnizados fue de 245,2 días, también con una alta variabilidad entre ambos extremos ${ }^{25}$. Este estudio incluyó también una comparación de los casos indemnizados con una muestra de asuntos que concluyeron con condenas. No se detectaron diferencias significativas en los promedios de duración de las prisiones preventivas ni en otras variables como género y edad, entre otras que se midieron. Sí, en cambio, se apreció una diferencia relevante respecto a los tipos de delitos, con una tendencia a imputaciones por figuras más graves tratándose del grupo que no fue condenado o, como

${ }^{22}$ GonZález, Augusto, cit. (n.19), p. 277.

${ }^{23}$ Sánchez, Nuria - Sobral, Jorge - Seijo, María Dolores, El error judicial en el uso de la prisión preventiva: personas en prisión que nunca llegan a ser condenadas, en Revista Iberoamericana de Psicología y Salud, 8 (2017) 1, pp. 36-43, p. 38. Cabe señalar que la identificación de sentencias se hizo sobre la base de datos de la Editorial Aranzadi. Por otra parte, los autores no distinguieron el título de imputación que dio origen a la indemnización por lo que es posible que algunos de ellos se hayan generado como caso basado en una solicitud de funcionamiento anormal.

${ }^{24}$ Sánchez, Nuria - Sobral, Jorge - Seijo, María Dolores, cit. (n. 23), p. 40. El mínimo habría sido de EU\$2.100 y el máximo de EU\$237.338. González informa el año 2008 que el Ministerio de Justicia en sede administrativa habría estado trabajando con un baremo de EU\$ 3.600 al mes (EU\$ 120 diarios), pero sin embargo el Tribunal Supremo no contaría con un criterio uniforme a esa fecha. Véase, GonZález, Augusto, cit. (n.19), p. 249.

${ }^{25}$ Sánchez, Nuria - Sobral, Jorge - Seijo, María Dolores, cit. (n. 23), p. 40. El mínimo habría sido de 3 días y el máximo de 785 . 
señalan también sus autores, de "delitos altamente estigmatizantes y con fuertes repercusiones mediáticas" ${ }^{26}$. Esto mostraría en cierta medida una mayor disposición del sistema español a utilizar la prisión preventiva en los asuntos más graves, aún sin considerar la fortaleza del caso, fenómeno que en nuestro país también ha sido identificado en investigaciones empíricas sobre su uso ${ }^{27}$.

Si bien el porcentaje de casos estimados favorablemente es relativamente magro, me parece que desde el punto de vista positivo estamos en presencia de una regla que ha demostrado un mayor rendimiento si uno la compara, por ejemplo, con nuestro artículo 19 no 7 letra i) de acuerdo a los datos entregados en la introducción. Esto, además, considerando que incluso el volumen total de personas en prisión preventiva en el promedio diario en Chile sería superior al de España, según muestran cifras que dispongo ${ }^{28}$. Por otra parte, los montos promedios de las indemnizaciones efectivamente obtenidas no serían bajos en relación al promedio de días de privación de libertad.

Desde un punto de vista crítico, en cambio, es posible notar cómo este título de imputación contenido en una regulación amplia, al menos en comparación con los estándares internacionales, no se ha concretado en una práctica indemnizatoria tan frecuente ni robusta. En parte, esto se explica por la configuración previa de la regla y la jurisprudencia generada en el período de su vigencia ${ }^{29}$. Sobre estos elementos me detengo en la sección que sigue.

${ }^{26}$ Sánchez, Nuria - Sobral, Jorge - Seijo, María Dolores, cit. (n. 23), p. 41.

${ }^{27}$ Duce, Mauricio - Riego, Cristián, La prisión preventiva en Chile: análisis de los cambios legales y su impacto (Santiago, Ediciones Universidad Diego Portales, 2011), pp. 159-161.

${ }^{28}$ En el estudio de Sánchez y otros se afirma que al año 2014 había 8.595 personas en prisión preventiva en cárceles españolas como promedio diario. SÁNCHEZ, Nuria - Sobral, Jorge - Seijo, María Dolores, cit. (n. 23), p. 36. En Chile, ese mismo año, según cifras de Gendarmería el promedio diario habría sido de 11.269 personas. Véase, Gendarmería de Chile, Compendio estadístico penitenciario (Santiago, 2014), p. 46. Según cifras de la Defensoría Penal Pública ese mismo año hubo 2.465 imputados atendidos por la institución que estuvieron en prisión preventiva y no fueron finalmente condenados. Véase, Defensoría Penal Pública, Informe Estadístico 2014 (Santiago, 2014) [http://www.dpp.cl/repositorio/148/399/estadisticas_2014].

${ }^{29}$ SÁnCHEZ, Miguel, Consecuencias imprevistas de la presunción de inocencia. La revisión de la doctrina del Tribunal Supremo sobre la responsabilidad por error judicial por efecto de la sentencia Tendam del Tribunal Europeo de Derechos Humanos, en Revista Justicia Administrativa, 55 (2012), pp. 49-64, p. 51. Cobreros, el año 2019, señala que luego del cambio jurisprudencial del Tribunal Supremo del año 2010 que restringió los alcances de la indemnización, según veré en lo que sigue, sólo se 


\section{La evolución de la regla de indemnización por prisión preventiva}

Hasta antes de la decisión del Tribunal Constitucional de junio de 2019, el artículo 294.1 de la LOPJ incluía como un elemento de restricción adicional a la procedencia de este derecho el que la absolución o el sobreseimiento libre se hubieran basado en la "inexistencia del hecho imputado". Al alero de esta redacción se generó una fuerte disputa interpretativa de los reales alcances de este derecho tanto en la doctrina como en la jurisprudencia, la que puede ser resumida a muy grandes rasgos en tres etapas previas a la situación actual.

En un momento breve inicial de vigencia de esta norma, que se extendió hasta el año 1989, el Tribunal Supremo la interpretó de manera estricta, comprendiendo que sólo cubría los casos en que la absolución o el sobreseimiento libre se fundaban en la inexistencia del hecho que originalmente había sido imputado a la persona que estuvo en prisión preventiva (inexistencia material u objetiva) y, además, interpretando literalmente que ello sólo podía proceder cuando se dictare sentencia absolutoria y sobreseimiento libre ${ }^{30}$.

A partir de un conjunto de decisiones del Tribunal Supremo desde enero de 1989, poco a poco se consolidó una nueva línea jurisprudencial que estuvo vigente hasta el año 2010. Esta, que constituiría lo que se podría identificar como la segunda etapa, ${ }^{31}$ se ha descrito como "expansiva y favorable a la declaración de responsabilidad del Estado" 32 o como una "interpretación extensiva" ${ }^{33} \mathrm{o}$, simplemente, como más flexible ${ }^{34}$. Dos elementos centrales caracterizaron al período. El primero y más importante es una ampliación interpretativa significativa del alcance de la expresión “inexistencia del hecho imputado". En efecto, la jurisprudencia entendió que no sólo se refería a inexistencia objetiva, sino que incluiría la "subjetiva", es decir, casos en que se dio por acreditada la falta de participación del acusado (no simplemente cuando hubiera falta de prueba sobre ello). El Tribunal Supremo justifica el abandono del tenor literal estricto por

habría dado lugar a una solicitud por dicho tribunal. Véase, Cobreros, Edorta, cit. (n.16), p. 28.

${ }^{30}$ Oubiña, Sabela, Artículo 121, ahora en: Cazorla, Luis María (Director) - Palomar Alberto, Comentarios a la Constitución Española de 1978 (Madrid, Thomson Reuters Aranzandi, 2018), tomo II, pp. 632-665, p. 658; DíAZ, Francisco, La presunción de inocencia y la indemnización por prisión preventiva (Valencia, Tirant lo Blanch, 2017), p. 189 (respecto del tema de la inexistencia del hecho).

${ }^{31}$ SÁncheZ, Miguel, cit. (n.29), pp. 54-55.

${ }^{32}$ Domenech, Gabriel, cit (n.11), p. 8.

${ }^{33}$ Cobreros, Edorta, cit. (n.16), p. 20.

${ }^{34}$ GonZÁlez, Augusto, cit. (n.19), pp. 244-247; Oubiña, Sabela, cit. (n. 30), p. 568. 
razones teleológicas o finalistas ${ }^{35}$. Pero, además, la comprensión de la inexistencia objetiva se amplió cubriendo casos de inexistencia jurídica o falta de tipicidad de los hechos imputados ${ }^{36}$.

El segundo aspecto en donde se produjo una ampliación de la interpretación estricta en esta etapa fue en materia del tipo de resoluciones judiciales que podían considerarse para efectos de estar cubiertas por el 294.1 de la LOPJ (sentencias absolutorias y sobreseimientos libres). Así, el Tribunal Supremo también señaló que el auto de sobreseimiento provisorio podía equipararse al libre cuando se encontrare firme y se haya retirado también la acusación de parte del Ministerio Fiscal ${ }^{37}$.

La tercera etapa se desarrolló a partir del 23 de noviembre del año 2010, fecha en la que el Tribunal Supremo intenta hacerse cargo de la jurisprudencia desarrollada por la Corte Europea de Derechos Humanos. A esa fecha había dos casos en que se condenó a España por violación del derecho a la presunción de inocencia (artículo 6.2 del Convenio Europeo) como consecuencia del tratamiento hacia a personas que solicitaron indemnización por prisión preventiva injusta y que les fue denegada debido a la falta de certeza total de la inocencia de los requirentes (por tanto, por no acreditarse el supuesto de inexistencia subjetiva). La Corte Europea consideró que esta distinción entre casos en que se acreditaba la no participación y los que no había prueba suficiente afectaban el tratamiento como inocentes que debían tener las personas no condenadas ${ }^{38}$. En ese contexto, el Tribunal Supremo optó por el camino de restringir la interpretación que sostenía desde 1989 y volver a la tesis literal más estricta de que el único caso cubierto por el artículo 294.1 de la LOPJ era el de inexistencia objetiva, evitando así incurrir en razonamientos que potencialmente podría

${ }^{35}$ Díaz, Francisco, cit. (n. 30), pp. 188-189; Domenech, Gabriel, cit (n.11), p. 8; GonZÁlez, Augusto, cit. (n.19), p. 236.

${ }^{36}$ Díaz, Francisco, cit. (n. 30), p. 189.

${ }^{37}$ OubiÑA, Sabela, cit. (n. 30), p. 659. En lo que se refiere al levantamiento del procesamiento el Tribunal Supremo sostuvo una posición más estricta aceptándolo sólo en casos ocasionales (p. 660).

${ }^{38}$ Se trata de los casos Puig Panella c. España de 25 de abril de 2006 y Tendam c. España de 13 de julio de 2010, ratificados también en un caso posterior como el de Boddy y Lanni c. España de 16 de febrero de 2016. 
afectar a la presunción de inocencia ${ }^{39}$. Sin embargo, esta interpretación fue objeto de diversas críticas ${ }^{40}$.

La paradoja que se da con esta solución es que, a partir de una decisión de la Corte Europea destinada a aumentar el nivel de protección de derechos de los justiciables, el Tribunal Supremo opta por un camino que reduce significativamente la protección que hasta el momento se había ofrecido en España a las personas que habían sido objeto de prisión preventiva y luego no había resultado condenadas ${ }^{41}$. Con todo, el Tribunal Supremo se encarga de afirmar que no necesariamente los casos de inexistencia subjetiva quedarían sin protección ya que, al menos una porción de ellos, podrían obtener reparación por las vías del error judicial o del funcionamiento anormal de la justicia ${ }^{42}$.

Este escenario cambia de manera significativa a partir de la decisión del Tribunal Constitucional de junio de 2019. Explico esto en la siguiente sección.

\section{La regulación vigente de la indemnización por prisión preventiva}

Desde el año 2017, el Tribunal Constitucional comienza a manifestar una posición crítica hacia la jurisprudencia desarrollada por el Tribunal Supremo al constatar que ella podría afectar la presunción de inocencia. De esta forma, ese año acoge dos recursos de amparo presentados por demandantes a quienes no se dio lugar a una solicitud de indemnización en casos de inexistencia subjetiva, poniendo en duda la constitucionalidad de la interpretación restrictiva asumida luego de $2010^{43}$.

La situación concluye con el pronunciamiento del Tribunal Constitucional en su decisión de junio de 2019. En esta, se elimina la frase que ya

${ }^{39}$ Con más detalle sobre historia de este cambio judicial recomiendo ver, Cobreros, Edorta, cit. (n.16), pp. 18-29; Díaz, Francisco, cit. (n. 30), pp. 189-190; Domenech, Gabriel, cit (n.11), pp. 9-12, OubiÑa, Sabela, cit. (n. 30), pp. 661662; SÁncheZ, Miguel, cit. (n.29), pp. 56-62; SAZ, Silvia, La obligación del Estado de indemnizar los daños ocasionados por la privación de libertad de quien posteriormente no resulta condenado, en Revista de Administración Pública, 195 (2014), pp. 55-98, pp. 90-95.

${ }^{40}$ Un resumen de las principales puede encontrarse en SAZ, Silvia, cit. (n. 39), pp. 95-97.

${ }^{41}$ En esta misma línea: Cobreros, Edorta, cit. (n.16), pp. 28-29; SÁncheZ, Miguel, cit. (n.29), pp. 49-64.

${ }^{42}$ Domenech, Gabriel, cit (n.11), p. 11. Saz sostiene que el problema se encuentra en fundar estos casos de responsabilidad en el artículo 121 de la Constitución (casos de error judicial) y no en cambio en el artículo 17 referido a la protección de la libertad individual. Véase: SAZ, Silvia, cit. (n. 39).

${ }^{43}$ Cobreros, Edorta, cit. (n.16), pp. 29-30; Medina, Luis, cit. (n. 15), pp. 5-6. 
he mencionado, lo que en la práctica significan una apertura del artículo 294.1 de la LOPJ ${ }^{44}$. En efecto, en el tenor literal actual no existe limitación para la procedencia de la indemnización más allá del tipo de resolución y que se haya causado un daño al solicitante, reforzando así el componente de responsabilidad objetiva de la norma. Con todo, como veré un poco más adelante, esto no establece un sistema automático de reparación.

No puedo entrar al detalle de la argumentación sostenido por el Tribunal Constitucional en su extensa sentencia en este punto porque ello me alejaría de los objetivos de este trabajo. Basta mencionar que los fundamentos principales descansan en la infracción al principio de igualdad contenido en la Constitución (artículo 14), al considerarse que restringir el artículo 294.1 de la LOPJ sólo a casos de inexistencia de hechos establecía una diferencia que carecía de una justificación razonable y que, además, resultaba desproporcionada ${ }^{45}$. Por otra parte, el Tribunal Constitucional considera que en su redacción e interpretación vigentes a ese momento se producía una incompatibilidad estructural con la garantía de presunción de inocencia contenida en el artículo 24.2 de la Constitución española de $1978^{46}$.

Dos elementos adicionales. El primero, es que el Tribunal Constitucional se detiene en el análisis de la finalidad o sentido del artículo 294 de la LOPJ ${ }^{47}$. En esta dirección concluye que la exposición de motivos de la LOPJ no informa sobre la materia, pero que es posible concluir que su existencia, por su configuración específica que permite reparar casos en que la prisión preventiva haya sido adoptada legalmente y sin error, se justifica por la singularidad del derecho involucrado con su uso y por la magnitud de la injerencia que ella supone causando efectos en extremo gravosos. Bajo esa perspectiva, la sentencia ancla la indemnización en estos casos en la idea de que ella corresponde a una situación de "daño sacrificial” de la libertad ${ }^{48}$ regulada por el legislador, que es consecuencia

${ }^{44}$ Cobreros caracteriza esto como un aumento exponencial del ámbito de aplicación del resarcimiento estatal en esta materia. Cobreros, Edorta, cit. (n.16), p. 35.

${ }^{45}$ STC 85/2019 de 19 de junio de 2019, párrafos 6 a 9 de la sección fundamentos jurídicos.

${ }^{46}$ STC 85/2019 de 19 de junio de 2019, párrafos 10 a 12 de la sección fundamentos jurídicos.

${ }^{47}$ STC 85/2019 de 19 de junio de 2019, párrafo 5 de la sección fundamentos jurídicos.

${ }^{48}$ La idea del "daño sacrificial", es decir, la de que existen "daños lícitamente causados por el poder público que, sin embargo, han de ser indemnizados para preservar la eficacia de los derechos de los ciudadanos que se ven singularmente afectados”. Véase, RodrígueZ, Ignacio, La dimensión constitucional del daño sacrificial, 
de una medida como la prisión preventiva que representa un sacrificio instrumental de la libertad con un carácter aflictivo extraordinario ${ }^{49}$. El Tribunal Constitucional resume su análisis en este punto señalando: "En suma, la persecución de intereses objetivos vinculados a la protección de la comunidad permite la limitación del derecho inviolable a la libertad, en las condiciones y en los casos previstos por la ley, pero también activa un mecanismo de compensación del extraordinario sacrificio que impone" ${ }^{50}$. Lo interesante de esta reflexión es que abandona por completo la idea que el fundamento de la indemnización por uso indebido o injusto de la prisión preventiva surge asociada al problema del error en el sistema judicial o a ser una forma específica de funcionamiento anormal, independizándola de esta forma de los otros dos títulos de imputación contenidos en la Constitución y la LOPJ ${ }^{51}$.

El segundo aspecto que destaco se refiere a los alcances de esta decisión del Tribunal Constitucional. Como ya señalaba, una primera lectura que sería posible abordar es que, a partir de ella, todo caso de una persona que estuvo en prisión preventiva y que no resulta condenada (ya sea por absolución o sobreseimiento libre) tendrá derecho a obtener indemnización de parte del Estado de una manera relativamente automática para todos quienes se encuentren en esa situación ${ }^{52}$. En la parte final de su decisión, el Tribunal se hace cargo en forma explícita de esta materia sosteniendo

en Revista de Derecho Constitucional, 29 (2019), pp. 1-46, p. 2, tiene larga tradición en el sistema español de responsabilidad estatal. Al aplicarla a este ámbito explica la razón por la cual el Estado se compromete a reparar daños ya que “....al contemplar normativamente al instituto de la prisión provisional, el Estado está asumiendo el riesgo, estadísticamente comprobado, de que algunos ciudadanos inocentes se vean privados de libertad, riesgo que el poder público decide asumir por el coste social que supondría prescindir de la prisión provisional. Acepta, por ello, la posibilidad que determinados individuos, que nada tienen que ver con el delito, sufran una gravísima intromisión en su libertad personal...", Véase, RodríGuez, Ignacio, cit. (n. 48), pp. 36-37.

${ }^{49}$ Una revisión de su historia y fundamentos puede verse en RoDRíGUEZ, Ignacio, cit. (n. 48). Sobre esta materia en particular analizando la sentencia del Tribunal Constitucional, véase: Medina, Luis, cit. (n. 15), pp. 7-18.

${ }^{50}$ STC 85/2019 de 19 de junio de 2019, párrafo 5 de la sección fundamentos jurídicos (párrafo final).

${ }^{51}$ Medina, Luis, cit. (n. 15), p. 7.

${ }^{52} \mathrm{Al}$ saberse la decisión del Tribunal Constitucional, pero todavía no conocerse sus fundamentos y detalle, parte de la doctrina manifestaba preocupación por un escenario de este tipo y hacía un llamado a limitar algo el alcance del artículo 294.1 señalando que los tratados internacionales no establecían un deber tan amplio de indemnización y que en principio lo lógico era reparar sólo casos de daños injustos. Cobreros, Edorta, cit. (n.16), pp. 36-37. Antes de esta decisión otros ya sostenían 
que su decisión no tiene por objeto establecer un sistema de indemnización automática. Se postula que el legislador tendrá libertad para acotar los presupuestos y alcances del artículo 294.1 de la LOPJ y, aun antes de eso y en su ausencia, éste deberá ser desarrollado mediante "....interpretaciones congruentes con su finalidad y con la teoría general de la responsabilidad civil que realicen la administración y, en último término, los órganos judiciales"s3. El Tribunal menciona como ejemplos de estos elementos de la responsabilidad civil la compensatio lucri cum damno y la relevancia de la conducta de la propia víctima. Autores como Medina Alcoz luego han desarrollado pautas bastante detalladas de cómo estos elementos debieran ser ponderados para efectos de determinar la existencia o no de una indemnización en el caso concreto ${ }^{54}$.

El artículo 294 de la LOPJ regula otras dos materias que no fueron alteradas por la decisión del Tribunal Constitucional y que describo brevemente para completar el cuadro de la regulación vigente en la materia. El artículo 294.2 establece un criterio para determinar la cuantía de la indemnización que debe considerar el tiempo de privación de libertad y las consecuencias personales y familiares que se hayan sufrido con ellas. Se trata de otra materia en la que no existe posibilidad de un comportamiento automático por parte de los órganos que toman la decisión, debido a la inexistencia de un baremo constitucional o legal específico ${ }^{55}$.

Una última materia que regula la LOPJ está contenida en el artículo 294.3 y se refiere al procedimiento a seguir en estos casos. Este se sujeta a la misma tramitación prevista para las situaciones de funcionamiento anormal, es decir, se permite recurrir directamente al Ministerio de Justicia a solicitar la indemnización sin tener que pasar previamente por el Tribunal Supremo.

Como se podrá apreciar, la reciente decisión del Tribunal Constitucional ha significado una ampliación muy relevante de la posibilidad de obtener indemnizaciones por prisiones preventivas. A la fecha, el legislador español no ha reaccionado con alguna regulación complementaria que precise alcances y límites del artículo 294.1 de la LOPJ, como tampoco existe un tiempo suficiente acumulado para evaluar el impacto que esta decisión ha tenido en la práctica del sistema ${ }^{56}$. Todo debiera indicar que a

la inconveniencia de indemnizar todos los casos. Véase: Domenech, Gabriel, cit (n.11), pp. $1-42$.

${ }^{53}$ STC 85/2019 de 19 de junio de 2019, párrafo 13 de la sección fundamentos jurídicos.

${ }^{54}$ Medina, Luis, cit. (n. 15), pp.19-26.

${ }^{55}$ Medina, Luis, cit. (n. 15), p. 20.

${ }^{56}$ Valga la pena señalar que tratándose de los efectos temporales de esta decisión 
un breve plazo se debiera producir un aumento importante en el número de solicitudes y de casos estimados favorablemente. Con todo, las resistencias en esta materia a veces se sobreponen a las regulaciones legales vigentes, por lo que será necesario hacer seguimiento sobre esto.

\section{OTROS MODELOS DE RESPONSABILIDAD EUROPEOS A OBSERVAR}

Como anuncié, mi idea en este capítulo es revisar en forma menos detallada otros dos ejemplos de legislación europea en la materia que podrían cubrir casos de privaciones de libertad erróneas. Mi objetivo es dar una vista panorámica general de casos interesantes de tener a la vista como opciones posibles de regulación, pero que es necesario estudiar con mayor profundidad no sólo en su configuración sino también en su funcionamiento práctico.

Como ya he señalado, no existe una categoría específica de mecanismos para reparar el problema de las privaciones de libertad erróneas, pero la regulación de sistemas de compensación frente a diversos tipos de daños causados por un proceso penal, paradigmáticamente cuando se usa prisión preventiva, permitirían considerarlo sucedáneos para lidiar con este problema.

\section{Alemania: la diversidad de vías indemnizatorias}

El caso alemán pareciera ser un buen ejemplo de cómo la reparación de víctimas de privaciones de libertad erróneas se podría lograr a través de diversos mecanismos. Se trata, además, de un país con larga tradición en leyes especiales dedicadas a la reparación de personas que han sido objeto de un proceso penal ${ }^{57}$.

El principio básico sobre el cual se construye el modelo alemán es que, al igual que en España, la responsabilidad por daños causados por la actividad judicial es del Estado y no de los jueces en particular, salvo

el Tribunal Constitucional explícitamente señala que ella no es aplicable a procesos fenecidos, sino sólo es eficaz en nuevos supuestos o en procedimientos ya iniciados en los que no haya recaído una resolución firme. STC 85/2019 de 19 de junio de 2019, párrafo 13 de la sección fundamentos jurídicos.

${ }^{57}$ Giuriati y Borchard identifican en sus trabajos que la legislación prusiana de 1766 sería la precursora en Europa en materia de reparación de condenas erróneas. Véase, Giurarti, Domenico, Errores judiciales: diagnósis y remedios (Santiago, Ediciones Olejnik, 2018), p. 155; BorChard, Edwin, cit. (n. 11), p.689. En esta materia específica, la ley de 14 de julio de 1904 se introdujo la situación de las personas inocentes en prisión preventiva como supuesto para obtener indemnización. Acosta, Pablo, Responsabilidad del Estado-juez (Madrid, Editorial Montecorvo, 2005), p. 66; Rebollo, Luis, cit. (n. 12), p. 70. 
casos calificados de actuación ilegítima ${ }^{58}$. A partir de ello, en la actualidad se prevén varios estatutos que permiten solicitar indemnización más allá de los casos de condenas erróneas.

Roxin reporta que el imputado está autorizado a iniciar un procedimiento con este objetivo en varias situaciones ${ }^{59}$. La primera, se trata de los casos de una persecución penal desde sus inicios ilegítima, es decir, en colisión con las normas de la Ordenanza Procesal Penal Alemana. A ello agrega casos de ilegitimidad fundados en disposiciones como el artículo 5.5 del Convenio Europeo referido a detenciones ilegales ${ }^{60}$.

Un segundo título indemnizatorio se referiría a casos en los que se puede solicitar la compensación aun cuando las autoridades hubieran actuado conforme a derecho o legalmente. Este título surgiría de la regulación de 1971 conocida como la Ley sobre resarcimiento de medidas de persecución penal del 8 de marzo de ese año ${ }^{61}$, que ha sido objeto de diversas modificaciones en el tiempo. El parágrafo 2 (1) de esta ley confiere el derecho a reclamar la indemnización al imputado que haya sufrido daños como consecuencia de que en el proceso hubiera sido objeto de prisión preventiva, internación, aprehensión provisional, secuestro y retiro provisional del permiso de conducir en caso de ser absuelto o el procedimiento dirigido en su contra haya sido sobreseído ${ }^{62}$.

Roxin explica que la ley distingue las consecuencias según si se trata de una absolución o un sobreseimiento. En el primer caso procede la indemnización salvo se den algunas de las situaciones reguladas como exclusiones en los parágrafos 5 y 6 de la ley ${ }^{63}$. Estas exclusiones hacen afirmar a Domenech que se trata de un sistema de responsabilidad que entregaría amplias facultades a los tribunales para admitir o denegar una solicitud de indemnización, citando, por ejemplo, el parágrafo 6(1)(2) que permite rechazar la solicitud si la absolución se produjo por un impedimento de tipo procesal ${ }^{64}$. Tratándose de un proceso concluido por sobreseimiento,

${ }^{58}$ Acosta, Pablo, cit. (n. 57), p. 66; González, Augusto, cit. (n.19), p. 30; Terhetche, Jorg, Judicial Accountability and Public Liability- the German "Judges Privilege" Under the Influence of European and International Law, en German Law Journal, 13 (2012) 3, pp. 313-330, pp. 316-320.

${ }^{59}$ Roxin, Claus, Derecho procesal penal (29a edición, traducción de Mario Amoretti y Darío Rolón, revisada por Ignacio Tedesco, Buenos Aires, Ediciones Didot, 2019), pp. 709-712.

${ }^{60}$ Roxin, Claus, cit. (n. 59), p. 709.

${ }^{61}$ Rebollo, Luis, cit. (n. 12), pp. 72-73.

${ }^{62}$ Acosta, Pablo, cit. (n. 57), p. 67; Domenech, Gabriel, cit (n.11), p. 13; Roxin, Claus, cit. (n. 59), p. 710.

${ }^{63}$ Roxin, Claus, cit. (n. 59), p. 710.

${ }^{64}$ Domenech, Gabriel, cit (n.11), p. 13. 
si el caso debe ser concluido por esa vía hay un derecho automático a la reparación. En cambio, tratándose de situaciones en que esta forma de término surge como una ponderación del tribunal, la indemnización dependerá de la discreción del mismo ${ }^{65}$. Estas distinciones pondrían un matiz en relación al alcance de la discrecionalidad judicial identificado por Domenech para decidir sobre el punto.

Finalmente, un tercer título de indemnización ha surgido a partir de una reciente ley elaborada con el objeto de incorporar en la legislación interna algunas decisiones de la Corte Europea de Derechos Humanos en contra de Alemania. Se trata de una ley de 2 de diciembre de 2011, que introdujo el parágrafo 198 a la GVG (Código de Constitución de Cortes) y que tiene por propósito indemnizar casos en los que ha existido una excesiva duración de los procesos en todo tipo de materias (no penales exclusivamente) ${ }^{66}$. La indemnización cubriría tanto perjuicio patrimonial material e inmaterial y concede EU\$ 1.200 por cada año de retraso ${ }^{67}$. Con todo, esta nueva regulación se ha criticado debido a que se trataría de una regla extremadamente limitada en cuanto al ámbito de procedencia ya que sólo se haría exigible en casos de excesiva duración y de clara y especial inactividad del sistema ${ }^{68}$.

Finalmente, se ha agregado más recientemente una nueva hipótesis de reparación en favor de imputados en casos en que "existen motivos para preocuparse de que el proceso no será concluido en un tiempo proporcionado" en el parágrafo 198 (3) de la GVG ${ }^{69}$.

Como se puede apreciar en esta somera revisión, el caso de Alemania presenta interés ya que ha ido ampliando paulatinamente en el tiempo las vías para obtener indemnización en diversas situaciones que el proceso penal puede generar daños. Desafortunadamente, carezco de evidencia empírica que muestre el funcionamiento de estas reglas en la práctica. Si ellas se cumplen de acuerdo al parámetro normativo sería posible pensar que entregan una cobertura más amplia que lo que hemos estudiado hasta el momento, pero se debe ser cauteloso por la enorme brecha que en estas materias suele existir entre norma y práctica.

${ }^{65}$ Roxin, Claus, cit. (n. 59), p. 710, situación similar ocurriría en las hipótesis en que el tribunal prescinde de pena o cuando las sanciones impuestas en la sentencia son inferiores a las consecuencias ya sufridas por el imputado.

${ }^{66}$ Terhetche, Jorg, cit. (n. 58), p. 328.

${ }^{67}$ Roxin, Claus, cit. (n. 59), p. 711.

${ }^{68}$ Terhetche, Jorg, cit. (n. 58), p. 328.

${ }^{69}$ Roxin, Claus, cit. (n. 59), pp. 711-712. 


\section{Holanda: ¿un estatuto generoso en su práctica?}

Otro ejemplo que me parece interesante revisar se refiere al caso de Holanda. Este país mantiene aún uno de los procesos penales de mayor apego a los sistemas inquisitivos de justicia vigente en Europa ${ }^{70} \mathrm{y}$, por otra parte, tiene números de población y flujos de casos del sistema relativamente similares a los nacionales como veré.

En la legislación procesal penal de Holanda también se contempla la posibilidad de que un imputado que ha sido objeto de privación de libertad durante el desarrollo del proceso pueda solicitar compensación por los daños causados invocando diversos títulos de imputación. El primero corresponde, al igual que en Alemania, al caso establecido en el artículo 5.5 del Convenio Europeo de Derechos Humanos que prevé el derecho a indemnización si se produce una detención ilegal ${ }^{71}$.

Existen dos vías más para intentar obtener una indemnización, una en la que incluso se podría solicitar en el evento que la privación de libertad haya sido decretada en forma legal ${ }^{72}$. En efecto, el artículo 89.1 del Código de Procedimiento Penal de dicho país establece el derecho que tiene de cualquier sospechoso que haya sido detenido y cuyo proceso no haya concluido con sanciones en su contra a solicitar una compensación por los daños ocasionados, los cuáles podrían ser pecuniarios y no pecuniarios ${ }^{73}$. A

${ }^{70}$ Una descripción detallada del proceso penal holandés en TAK, Peter, The Dutch Criminal Justice System (The Hague, Boom Juridische uitgevers, 2003), pp. 19-69; y Crijins, J.H - VAn DER Woude, M.A.H, The criminal justice system, ahora en Introduction to Dutch Law (The Netherlands, Wolters Kluwer, 2016), pp. 441-474.

${ }^{71}$ TAK, Peter, cit. (n. 70), p. 60. Esta demanda tendría que presentarse ante tribunales civiles a diferencia de los mecanismos que revisaré a continuación. Sentencia de la Corte Europea de Derechos Humanos, Case Masson and Van Zon v. The Netherlands, 28 de septiembre de 1995, párrafo 33.

${ }^{72}$ Una transcripción completa de las reglas relevantes que analizaré, en idioma inglés, se puede encontrar en Sentencia de la Corte Europea de Derechos Humanos, Case Masson and Van Zon v. The Netherlands, 28 de septiembre de 1995, párrafos 26 a 31. La lectura del caso entrega también una buena explicación de los dos mecanismos que revisaré y de su uso en la práctica, pero es algo antiguo, aún cuando no parecieran existir discrepancias con la descripción que realiza la doctrina más actualizada que he revisado sobre la materia.

${ }^{73}$ TAK, Peter, cit. (n. 70), p. 60, ZÚNIGA, Bárbara, Procedencia de la indemnización por error judicial respecto del imputado privado de libertad durante la investigación y cuyo proceso no termina con una sentencia condenatoria (Santiago, Trabajo final de titulación para optar al grado de Magíster en Derecho Penal y Procesal, Facultad de Derecho, Universidad Diego Portales, 2018), pp. 46-47. Véase también la explicación entregada por el sistema estadístico holandés StatLine en la nota explicativa de las cifras que entregaré y que puede revisarse en https://opendata.cbs.nl/statline/\#/CBS/ en/dataset/37632ENG/table?fromstatweb [visitado el 15 de junio del año 2020]. 
pesar de esta redacción, que en principio parece establecer un sistema de responsabilidad objetivo y automático, el artículo 90.1 del Código cualifica la posibilidad de obtener indemnización a que el tribunal que conoce de la solicitud lo estime conveniente, para lo cual debe tener en cuenta todas las circunstancias e identificar que existen motivos o razones de equidad para su concesión. Según Domenech esto, al final de cuentas, se traduce en que el legislador entrega amplia discrecionalidad a los tribunales para decidir otorgar o denegar las indemnizaciones bajo este título ${ }^{74}$, lo que nos alejaría de estar en presencia de una norma que opere en forma automática. Esta lógica pareciera haberse recogido ampliamente por la jurisprudencia en Holanda ${ }^{75}$.

En cuanto a la indemnización misma, el artículo 90.2 del Código de Procedimiento Penal señala que para fijar el monto deberá considerarse las circunstancias personales del requirente. El artículo 90.4 permite, por su parte, que la compensación se produzca por vía de imputar los días privados de libertad al cumplimiento de penas por otros $\operatorname{casos}^{76}$. Finalmente, diversos instructivos dictados por el Poder Judicial de Holanda han fijado un baremo para indemnizar por cada día privado de libertad dependiendo del lugar en que esta se produce. Ese corresponde a EU\$ 105 por día en caso de haberse ejecutado en una celda de la policía, EU\$ 80 en una casa de preservación y EU\$ 105 en una prisión o cárcel de máxima seguridad. Se trataría, en todo evento, de una guía y no de cifras obligatorias ${ }^{77}$.

En términos procedimentales, el artículo 89.3 del Código de Procedimiento Penal establece que la solicitud de indemnización debe presentarse dentro de los tres meses de concluido el caso y esta podría ser incluso solicitada por los herederos (artículo 89.6), caso en el cual la compensación no incluirá pérdidas no pecuniarias. Según el artículo 89.4 la cámara que conozca la solicitud debe estar integrada en la medida de lo posible por jueces que hayan intervenido previamente en el juicio.

${ }^{74}$ Domenech, Gabriel, cit. (n. 11), p. 13.

${ }^{75}$ ZúNiga, Bárbara, cit. (n. 73). Esta autora analiza varios fallos del año 2016 sobre esta materia. Este mismo criterio puede verse también en la sentencia del caso Masson y Van Zon en el que la indemnización solicitada por ambos fue rechazada por razones de equidad y la Corte Europea validó dicha decisión al establecer que no existía un derecho en el Convenio Europeo a la obtención de una compensación por la prisión preventiva sufrida en un caso por el sólo hecho de ser absueltos. La Corte también cita fallos holandeses de la década del 90 en la misma dirección. Sentencia de la Corte Europea de Derechos Humanos, Case Masson and Van Zon v. The Netherlands, 28 de septiembre de 1995, párrafos 32, 33 y 50.

${ }^{76}$ TAK, Peter, cit. (n. 70), p. 60.

77 ZúNiga, Bárbara, cit. (n.75), p. 49. Tak se refiere a EU\$ 100 diario sin hacer estas distinciones. Véase, TAK, Peter, cit. (n. 70), p. 60. 
Un segundo título de imputación está previsto en el artículo 519a del Código de Procedimiento Penal. Dicha norma establece que una persona que ha sido condenada tiene derecho a solicitar compensación en el evento de que la detención policial o la prisión preventiva haya sido ilegal para el delito específico por el cual fue privado de libertad ${ }^{78}$. Procedimentalmente se aplican las mismas reglas, por analogía, del mecanismo del artículo 89 según dispone el artículo 519a.4.

Según se puede apreciar, se trataría de una situación completamente diferente que descansa sobre la idea de ilegalidad de la detención que es objeto de indemnización, pero que tiene el aspecto interesante de explicitar que esa ilegalidad no se "blanquearía" por la existencia de una condena en el caso.

Es importante también señalar que una misma persona podría recurrir por ambas vías mencionadas si es que se dieran las dos situaciones en su favor ${ }^{79}$.

Más allá de esta descripción de los títulos de imputación existentes, el caso holandés es interesante por la existencia de estadísticas oficiales que permiten conocer un poco mejor la forma en que en la práctica estas reglas se cumplen ${ }^{80}$. Así, en el año 2016, los datos indican que en virtud del artículo 89 del Código de Procedimiento Penal (casos de privaciones de libertad sin sanción) se presentaron 7.235 solicitudes de compensación en estas materias, siendo concedidas 6.222, es decir, un $86 \%$ de ellas. El monto total de las compensaciones otorgadas llegó a EU\$7,9 millones y el promedio concedido por solicitud fue de EU\$1.266. El número de peticiones e indemnizaciones concedidas ha crecido en forma sistemática y estable desde el primer año en que están disponibles los registros (1990 con 692 solicitudes y 451 concedidas), sin embargo, el monto promedio de 2016 es más bajo que el año 1990 (EU\$2.065), el año 2000 (EU\$2.538) y el 2010 (EU\$ 2.189) por mencionar algunos ejemplos del período. Se mantiene estable el porcentaje en que acogen solicitudes que se mueven

${ }^{78}$ TAK, Peter, cit. (n. 70), p. 60. También recomiendo ver la explicación entregada por el sistema estadístico holandés StatLine en la nota explicativa de las cifras que entregaré y que puede revisarse en https:/opendata.cbs.nl/statline/\#/CBS/ en/dataset/37632ENG/table?fromstatweb [visitado el 15 de junio del año 2020].

${ }^{79}$ Esto ocurrió, por ejemplo, en el caso de Masson y Van Zon. Allí su solicitud de indemnización fue aceptada por los tribunales de Holanda en virtud al artículo 591a, pero rechazada tratándose del artículo 89. Sentencia de la Corte Europea de Derechos Humanos, Case Masson and Van Zon v. The Netherlands, 28 de septiembre de 1995, párrafos 22 a 25 .

${ }^{80}$ Todos los datos que a continuación citaré provienen de StatLine, sistema estadístico de Holanda, disponible en: https:/opendata.cbs.nl/statline/\#/CBS/en/ dataset/37632ENG/table?fromstatweb [visitado el 15 de junio del año 2020]. 
entre el $80 \%$ y $90 \%$ y el gasto total no ha superado los EU\$ 11,1 millones anuales (años 2012 y 2013 como puntos más altos).

Tratándose del artículo 519a del Código de Procedimiento Penal, el año 2016 se habrían presentado 10.375 solicitudes de indemnización, de las cuáles se acogieron 9.680, es decir, un 93\%. El monto total de las compensaciones otorgadas llegó a EU\$15,3 millones y el promedio concedido por solicitud fue de EU\$1.576. Al igual que en el caso anterior, el número de solicitudes e indemnizaciones concedidas por este título ha crecido en forma sistemática y estable desde el primer año en que están disponibles los registros (1990 con 711 solicitudes y 564 concedidas). También ocurre que el monto promedio de 2016 es más bajo que el año 1990 (EU\$ 1.969), el año 2000 (EU\$ 3.513) y el 2010 (EU\$ 2.132) por mencionar algunos ejemplos del período. Se mantiene estable el porcentaje en que se acogen solicitudes que se mueven también entre el 80\% y 90\% y el gasto total no ha superado los EU\$ 16,4 millones anuales (año 2014 como punto más alto).

Para contextualizar el alcance de estas cifras me parece interesante tener presente algunos datos generales del sistema de justicia penal holandés y demográficos del país. Al año 2014, la justicia penal holandesa tenía alrededor de un millón de ingresos registrados por la policía (1.006.770), de los cuáles un 60\% estuvo constituido por delitos contra la propiedad ${ }^{81}$. Ese mismo año, el sistema alcanzó un poco menos de 160.000 condenas o equivalentes funcionales (entendidas como alguna respuesta de tipo punitivo que puso fin al caso) ${ }^{82}$. Su población al año 2018 era de 17,2 millones de habitantes aproximadamente ${ }^{83}$. Por otro lado, cifras del 2013 indicaban que el 39,9\% de la población penitenciaria eran personas en prisión preventiva ${ }^{84} \mathrm{y}$ un estudio sobre la práctica en el uso de esta medida cautelar indicaba que en un porcentaje mayoritario de los casos en que el fiscal la solicita, ésta se obtiene y que, en casi en todos ellos, el proceso terminó con una condena $(96,4 \%)^{85}$.

Como puede apreciarse, se trata de cifras similares de población que las de nuestro país y con ingresos y condenas del sistema de justicia penal porcentualmente comparables, aun cuando menores en términos abso-

${ }^{81}$ Crijins, J.H - VAn der Woude, M.A.H, cit. (n. 70), p. 443.

${ }^{82}$ Crijins, J.H - Van der Woude, M.A.H, cit. (n. 70), pp. 444-445.

${ }^{83}$ Disponible en: https://datosmacro.expansion.com/demografia/poblacion/ paises-bajos [visitado el 15 de junio del año 2020].

${ }^{84}$ Crijins, J.H - Leeuw, B.J.G. - Wermink, H.T., Pre-trail Detention in The Netherlands: Legal Principles Versus Practical Reality (The Hague, Eleven International Publishing, 2016), pp. 10-11.

${ }^{85}$ Crijins, J.H - Leeuw, B.J.G. - WerminK, H.T., cit. (n. 84), p. 28, 43. 
lutos que Chile ${ }^{86} \mathrm{y}$ con un uso similar de la prisión preventiva ${ }^{87}$. En este escenario, el hecho de que en el año 2016 se haya dado lugar a cerca de 16.000 solicitudes de indemnización por ambas normas revisadas y de tasas de aceptación de las solicitudes que se mueven entre 80 y $90 \%$, habla de una práctica completamente diversa en relación a la posibilidad concreta $\mathrm{y}$ vigencia real de las normas que establecen un derecho a obtener indemnización. Existiendo diferencias importantes en la configuración de ambos sistemas de justicia penal, mi punto es que en esta materia pareciera que la explicación no puede simplemente obedecer al carácter más inquisitivo del modelo holandés por sobre el nacional. Lo mismo podría argumentarse también tratándose del sistema español, y sin embargo Holanda también se distancia de la cobertura que hasta la fecha se ha dado en dicho país a los casos de personas sometidas a prisión preventiva que no han sido finalmente condenados.

\section{CONCLUSIÓN}

La revisión que he realizado del derecho comparado da cuenta de que la idea de compensar a las personas que han sufrido daños producto de privaciones de libertad tiene una importante recepción. Esto obedecería a que la reparación parece ser percibida de manera generalizada como

${ }^{86}$ El año 2018 el Ministerio Público registró 1,4 millones de delitos ingresados y un poco más de 210.000 condenas. Ministerio Público, Boletín Anual 2018 (Santiago, 2018). [http://www.fiscaliadechile.cl/Fiscalia/estadisticas/index.do].

${ }^{87}$ Según datos de Gendarmería de Chile de diciembre de 2019 el promedio de presos sin condena fue de $34,22 \%$ de la población penitenciaria. Disponible en: https://www.gendarmeria.gob.cl/estadisticaspp.html [visitado el 15 de junio del año2020]. De acuerdo a las cifras que proporciona el Poder Judicial en Chile, entre el año 2010 y junio de 2019 un poco menos que el 90\% de las solicitudes de prisión preventiva de los fiscales son concedidas (87,24\%). Disponible en: https://public. tableau.com/profile/poder.judicial\#!/vizhome/share

d/M5R57WYYY [visitado el 15 de marzo del año 2020]. Más allá de las similitudes estadísticas, sorprende también las prácticas en el uso de esta medida cautelar. Un estudio empírico en Holanda destinado a evaluar su uso concluyó que, si bien es cierto las reglas de dicho país eran compatibles con los estándares del Convenio Europeo de Derechos Humanos, se notaba con preocupación una tendencia a concederla en la gran mayoría de los casos que los fiscales la solicitan, y luego que existiría un problema con las justificaciones que dan los jueces al otorgarlas que suelen ser breves y basadas en consideraciones abstractas y, finalmente, se constataba que las necesidades de cautela invocadas para su uso se suelen dar por acreditadas con facilidad. Véase, Crijins, J.H - Leeuw, B.J.G. - Wermink, H.T., cit. (n. 84), p. 48. 
un elemento de justicia mínima para quienes han sufrido consecuencias, muchas veces gravísimas, producto de estas privaciones de libertad.

Esta noción de justicia se traduce luego en diversos tipos de diseño institucional para dar respuesta al problema. No obstante, en los ejemplos estudiados, se ha podido constatar que más allá de este reconocimiento normativo, existen serias dificultades para identificar una práctica robusta de reparación. En algunos casos las limitaciones provienen del propio diseño normativo que impone exigencias y cualificaciones muy estrictas, en otras de la interpretación restrictiva que hacen los órganos encargados de dicha labor. En este contexto, es difícil identificar una jurisdicción que cuente con un modelo completamente satisfactorio o que resuelva el problema de una manera que consensuadamente pueda sostenerse como equilibrada y adecuada.

Aun considerando lo anterior, el caso chileno pareciera ser uno extremo. Como señalé en la introducción, la evidencia disponible en nuestro país demuestra que quienes obtienen reparación en Chile son un grupo marginal dentro del universo posible y especialmente de quienes han sufrido errores tratándose de decisiones de prisión preventiva. Aún con todas las limitaciones y críticas que se formulan en sus propios países, los mecanismos comparados estudiados manifiestan mayores niveles de rendimiento y protección de las víctimas de estos errores.

Como es de público conocimiento, se ha iniciado en nuestro país un proceso que puede concluir con una nueva constitución, que seguramente otorgará una oportunidad para revisar la actual regulación del artículo 19 no 7 letra i). Recordemos que varios proyectos de ley presentados dan cuenta que desde hace tiempo se viene acumulando la sensación que estamos en una materia que requiere un nuevo equilibrio. Es en este contexto en el que el derecho comparado nos puede ayudar al entregarnos algunas pistas de cómo lograr una regulación y, especialmente, una práctica más satisfactoria.

Una primera cuestión es que la experiencia comparada parece demostrar que la ampliación de cobertura en la compensación, aún con temores similares a los que se dan en Chile respecto a su impacto presupuestario, no se traduce necesariamente en un "desangramiento económico" para los Estados. Incluso en el caso holandés donde aparentemente existe una práctica más abierta de compensación en materia de privaciones de libertad, no estamos en presencia de números que no sean abordables por nuestro país. Así, la experiencia comparada enseña que, aun manteniendo las preocupaciones históricas en esta materia, es posible avanzar bastante más en Chile.

Un segundo tema es que otorgar una mayor cobertura no es sinónimo a un sistema completamente abierto de reparación ante cualquier caso. 
Las soluciones de derecho comparado dan cuenta de diversas estrategias de regulación de las compensaciones, algunas más restrictivas y otras más abiertas, que ofrecen rangos interesantes para debatir hasta donde se quiere llegar en la materia. Mi inclinación personal es por un sistema generoso considerando el enorme impacto que tienen las privaciones de libertad erróneas en la vida de las personas. En esta dirección, por ejemplo, reglas como la holandesa y la española reciente a partir de la decisión del Tribunal Constitucional de 2019, me parecen alternativas atractivas. En el otro extremo, también las experiencias revisadas dan cuenta que parece ilusorio esperar que un sistema se configure como una respuesta automática a todos los casos sin criterios de discriminación.

Llama también la atención el enorme avance experimentado en las legislaciones revisadas respecto a la cobertura normativa y, al menos en el caso holandés, de la práctica del sistema de las restricciones de libertad en el proceso en los casos en que no se concluye con condena. Me parece que esta es una base sobre la cual construir un esquema de reparación más adecuado para los casos en estudio. Creo será importante ver cómo se desenvuelve en la práctica el sistema español en esta materia post decisión de su Tribunal Constitucional en junio de 2019 que aparentemente situaría a esta legislación como un sistema aún más generoso en este punto, pero focalizado a los casos de uso de la prisión preventiva y no a cualquier otra restricción a la libertad.

En fin, me parece que los ejemplos analizados ofrecen muchas otras ideas y nos permiten ponderar la situación nacional en un contexto más claro. En mi opinión es un área que debe reformarse, ya sea en el contexto del debate por una nueva constitución o fuera de este.

\section{BiBLIOGRAFÍA}

Acosta, Pablo, Responsabilidad del Estado-juez (Madrid, Editorial Montecorvo, 2005). BARros, Enrique, Tratado de responsabilidad extracontractual (Santiago: Editorial Jurídica de Chile, 2006).

BORCHARD, Edwin, European Systems of State Indemnity for Errors in Criminal Justice, en Journal of the American Institute of Criminal Law and Criminology, 3 (1912), pp. 684-718.

Campbell, Katryn - Denov, Myriam, The burden of innocence: coping with a wrongful imprisonment, en Canadian Journal of Criminal Law and Criminal Justice, 46 (2004), pp. 139-163.

Carmona, Carlos, La responsabilidad del Estado-juez: Revisión y proyecciones, en Revista de Derecho Público, 66 (2004), pp. 307-357.

Clow, Kimberly - Leach, Amy-May - Ricciardelli, Rosemary, Life After Wrongful Convictions, en CuTler, Brian (editor), Conviction of the Innocent (Washington, APA, 2012), pp. 327-341. 
Cobreros, Edorta, El sistema de indemnización por prisión provisional indebida en la encrucijada, en Revista de Administración Pública, 209 (2019), pp. 13-44.

Cobreros, Edorta, Funcionamiento anormal de la administración de justicia e indemnización, en Revista de Administración Pública, 177 (2008), pp. 31-69.

Crijins, J.H - Leeuw, B.J.G. - Wermink, H.T., Pre-trail detention in the Netherlands: legal principles versus practical reality (The Hague, Eleven International Publishing, 2016).

Crijins, J.H - Van der Woude, M.A.H, The criminal justice system, en Introduction to Dutch Law (The Netherlands, Wolters Kluwer, 2016), pp. 441-474.

Cristi, María Francisca, Responsabilidad del Estado por conductas injustificadamente erróneas o arbitrarias del Ministerio Público (Santiago, Tesina presentada a la Facultad de Derecho de la Universidad Finis Terrae para optar al grado de Magíster en Derecho Público, 2019).

Defensoría Penal Pública, Informe Estadístico 2014 (Santiago, 2014). [http://www. dpp.cl/repositorio/148/399/estadisticas_2014].

Defensoría Penal Pública, Informe Estadístico 2018 (Santiago, 2018). [visible en internet: http://www.dpp.cl/repositorio/177/486].

DíAZ, Francisco, La presunción de inocencia y la indemnización por prisión preventiva (Valencia, Tirant lo Blanch, 2017).

Díaz, Nataly - Muñoz, Pamela, La responsabilidad del Estado-Juez: Buenas razones para proponer una acepción amplia de error judicial en Chile, en Revista de Derecho Público, 83 (2015), pp. 37-60.

DOMENECH, Gabriel, ¿Es mejor indemnizar a diez culpables que dejar a un inocente sin compensación?, en InDret, 4 (2015), pp. 1-42.

Dorn, Carlos, Responsabilidad extracontractual del Estado por actos del Ministerio Público, en Revista de Derecho Editada por el Consejo de Defensa del Estado, 13 (2005), pp. 13-26.

Duce, Mauricio - Riego, Cristián, La prisión preventiva en Chile: análisis de los cambios legales y su impacto (Santiago, Ediciones Universidad Diego Portales, 2011).

Duce, Mauricio - Villarroel, Romina, Indemnización por error judicial: una aproximación empírica a la jurisprudencia de la Corte Suprema de los años 2006-2017, en Revista Politica Criminal, 14 (2019) 28, pp. 216-268.

Duce, Mauricio, Los recursos de revisión y la condena de inocentes en Chile: una aproximación empirica en el periodo 2007-2016, en Doctrina y jurisprudencia penal: Recursos de amparo y revisión, 30 (2017), pp. 3-40.

Evans, Enrique, Los derechos constitucionales (Santiago, Editorial Jurídica de Chile, 1986), II.

Garrido, Mario, La Indemnización por Error Judicial en Chile, en Revista Ius et Praxis, 5 (1999) 1, pp. 473-482.

Gendarmería de Chile, Compendio estadístico penitenciario (Santiago, 2014).

Giurarti, Domenico, Errores judiciales: diagnósis y remedios (Santiago, Ediciones Olejnik, 2018).

GonZÁlez, Augusto, Responsabilidad patrimonial del Estado en la administración de justicia (Valencia, Tirant lo Blanch, 2008).

GraU, Nicolás - Rivera, Jorge, Discriminación e impacto negativo de la prisión preventiva en la vida de las personas, en Revista 9319 (2018), pp. 26-29. 
Gross, Samuel - O'Brien, Barbara - Hu, Chen - KenNedy, Edward, Rate offalse convictions of criminal defendants who are sentenced to death, en Proceedings of the National Academy of Sciences of the United States of America, 11 (2014) 20, pp. 7230-7235.

Grounds, Adrian, Psychological consequences of wrongful convictions and imprisonment, en Canadian Journal of Criminal Law and Criminal Justice, 46 (2004), pp. 165-182.

Huenuqueo, Camila, El ilusorio ejercicio del derecho a indemnización por error judicial consagrado en el artículo $19 n^{\circ} 7$ letra $i$ de la Constitución como respuesta al uso de la prisión preventiva en Chile (Santiago, Seminario para optar al grado de Licenciado en Ciencias Jurídicas Universidad Diego Portales, 2020), 51 pp.

Medina, Luis, Razones para (no) indemnizar la prisión provisional seguida de absolución: guía explicativa del art. 294.1 LOPJ tras la STC 85/2019 de 19 de junio, en Revista Española de Derecho Administrativo, 200 (2019), pp. 1-41.

Ministerio Público, Boletín Anual 2018 (Santiago, 2018). [visible en internet: http:// www.fiscaliadechile.cl/Fiscalia/estadisticas/index.do].

MujIzI, Jamil, The right to compensation for wrongful conviction/miscarriage of justice in international Law, en International Human Rights Law Review, 8 (2019), pp. 215-244.

NowaK, Manfred, U.N. Covenant on Civil and Political Rights: CCPR Commentary (Germany, N.P Engel Publisher, 2005).

Oubiña, Sabela, Artículo 121, en Cazorla, Luis María (director) - Palomar, Alberto (colaborador), Comentarios a la Constitución Española de 1978 (Madrid, Thomson Reuters Aranzandi, 2018), II, pp. 632-665.

Rebollo, Luis, Jueces y responsabilidad del Estado: el artículo 121 de la Constitución (Madrid, Centro de Estudios Constitucionales, 1983).

Risinger, Michael, Innocent Convicted: An Empirically Justified Wrongful Conviction Rate, en The Journal of Criminal Law \& Criminology, 97 (2007) 3, pp. 761-806.

Rodríguez, Ignacio, La dimensión constitucional del daño sacrificial, en Revista de Derecho Constitucional, 29 (2019), pp. 1-46.

Roxin, Claus, Derecho procesal penal (29a edición, traducción de Mario Amoretti y Darío Rolón, revisada por Ignacio Tedesco, Buenos Aires, Ediciones Didot, 2019).

RuIz de VAlbuena, Irene, La justicia reduce su factura por errores judiciales (España, Cinco Días, El País Economía, 3 de noviembre de 2017) [visible en internet: https://cincodias.elpais.com/cincodias/2017/10/27/legal/1509097046_653926. html].

SÁNCHEZ, Miguel, Consecuencias imprevistas de la presunción de inocencia. La revisión de la doctrina del Tribunal Supremo sobre la responsabilidad por error judicial por efecto de la sentencia Tendam del Tribunal Europeo de Derechos Humanos, en Revista Justicia Administrativa, 55 (2012), pp. 49-64.

SÁncheZ, Miguel, Derecho administrativo parte general (Madrid, Tecnos, 2019).

SÁnchez, Nuria - Sobral, Jorge - Seijo, María Dolores, El error judicial en el uso de la prisión preventiva: personas en prisión que nunca llegan a ser condenadas, en Revista Iberoamericana de Psicología y Salud, 8 (2017) 1, pp. 36-43.

SAZ, Silvia, La obligación del Estado de indemnizar los daños ocasionados por la privación de libertad de quien posteriormente no resulta condenado, en Revista de Administración Pública, 195 (2014), pp. 55-98.

Schabas, William, The European Convention on Human Rights (Oxford, Oxford University Press, 2015). 
Scott, Leslie, It Never Ends: the Psychological Impact of Wrongful Convictions, en American University Criminal Law Brief, 5 (2010) 2), pp. 9-22.

TAK, Peter, The Dutch criminal justice system (The Hague, Boom Juridische uitgevers, 2003).

Terhetche, Jorg, Judicial accountability and public liability - the German "judges privilege" under the influence of European and international law, en German Law Journal, 13 (2012) 3), pp. 313-330.

Trechsel, Stefan, Human Rights in Criminal Proceedings (United Kingdom, Oxford University Press, 2006).

ZúNiga, Bárbara, Procedencia de la indemnización por error judicial respecto del imputado privado de libertad durante la investigación y cuyo proceso no termina con una sentencia condenatoria (Santiago, Trabajo final de titulación para optar al grado de Magíster en Derecho Penal y Procesal Facultad de Derecho Universidad Diego Portales, 2018).

ZúNiga, Francisco, La Acción de indemnización por error judicial. Reforma constitucional. regulación infraconstitucional y jurisprudencia, en Estudios Constitucionales, 6 (2008) 2, pp. 15-41.

\section{JURISPRUDENCIA CITADA}

Caso Masson and Van Zon v. The Netherlands (1995): Corte Europea de Derechos Humanos, 28 de septiembre de 1995.

Caso Puig Panella v. España (2006): Corte Europea de Derechos Humanos, 25 de abril de 2006.

Caso Tendam v. España (2010): Corte Europea de Derechos Humanos, 13 de julio de 2010.

STC 85/2019 de 19 de junio de 2019, en: BOE núm. 177, de 25 de julio de 2019. 